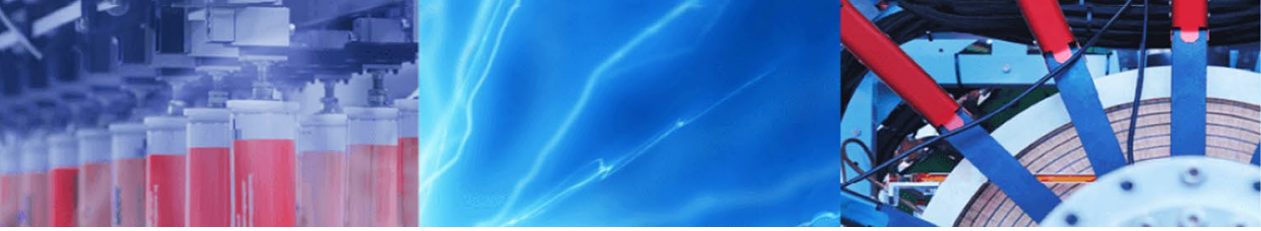

Research Article

\title{
Bacterial killing efficacy of synthesized rod shaped cuprous oxide nanoparticles using laser ablation technique
}

\author{
Abhishek K. Bhardwaj ${ }^{1} \cdot$ Vinay Kumar $^{2} \cdot$ Vivek Pandey $^{1} \cdot$ Ram Naraian $^{3} \cdot$ Ram Gopal $^{4}$ (I)
}

(c) Springer Nature Switzerland AG 2019

\begin{abstract}
Recent interests with copper nanoparticles (Cu-NPs) has arisen because of its low cost and antibacterial properties, as it may be one of the very important alternatives to silver NPs. Pulsed laser ablation of a solid target (copper) in liquid media is used to synthesize colloidal oxide copper $\left(\mathrm{Cu}_{2} \mathrm{O}\right.$ and $\mathrm{CuO}$ NPs) NPs. These oxides of copper NPs were synthesized using Nd:YAG laser energy to maintain a $40 \mathrm{~mJ} /$ pulse wavelength at $1064 \mathrm{~nm}$. During the synthesis of colloidal NPs only two conditions were opted, employing double distilled water (without PEG) and 10\% preparation of PEG. Both NPs were prepared under the similar parameters such as optimized instrument settings, laser energy and time of laser exposure ( $1 \mathrm{~h}$ ablation). Further, these copper oxide NPs were characterized by advance technologies including UV-visible, X-ray diffraction, transmission electron microscopy and attenuated total reflection Fourier transform infrared spectroscopy techniques. The significant antibacterial properties of synthesized materials were also observed. The cuprous oxide NPs, showed remarkable antibacterial effect conducted using disc diffusion techniques. The minimum inhibitory concentration and minimum bactericidal concentration of synthesized $\mathrm{Cu}_{2} \mathrm{O} \mathrm{NPs}$ were recorded as 120 and $140 \mu \mathrm{g} / \mathrm{L}$ respectively against Staphylococcus aureus used as positive control. Therefore, based on the findings of present study $\mathrm{Cu}_{2} \mathrm{O} \mathrm{NPs} \mathrm{can}$ be exploited as stable antimicrobial agents for multipurpose uses.
\end{abstract}

Keywords Copper oxide NPs · Antibacterial · Laser ablation · UV-visible · Polyethylene glycol

\section{Introduction}

In the era of rapid development of nanotechnology, continuous progress in the synthesis and self-assembly of nanomaterials in a controlled and repeatable manner has been a problem. Because of its possible potential applications in various research fields, it has attracted much attention $[1,16]$. Copper and copper-based nanoparticles (NPs) are of particular interest due to their several applications such as surface properties for low cost electronic devices, conductive films of researchers [20], lubricants, nanofluids, catalysis and antimicrobial activity, against bacteria, fungi, algae and viruses $[1,22,26]$. These characteristics make them particularly attractive for a broader range of multiple applications [13]. However, high oxidation tendency, extreme sensitivity to air creates difficulty in its stability of copper NPs [7]. Various methods have been accepted for the synthesis of copper NPs but most of them have encountered the formation of mixed phases, complex synthetic strategies, and structural formation control is poor $[4,19]$. But the laser ablation technique is simpler, with high purity and faster method of NPs synthesis than other methods. It involves ablating a solid target placed in a liquid environment to produce a NP collected as a colloidal dispersion. Laser ablation has the several advantages such as short reaction time, mild temperature conditions,

$\triangle$ Ram Gopal, profrgopal@gmail.com | 'Department of Environmental Science, Veer Bahadur Singh Purvanchal University, Jaunpur, India. ${ }^{2}$ Institute of Pharmacy, Veer Bahadur Singh Purvanchal University, Jaunpur, India. ${ }^{3}$ Department of Biotechnology, Veer Bahadur Singh Purvanchal University, Jaunpur, India. ${ }^{4}$ Laser Spectroscopy and Nanomaterials Lab, Department of Physics, University of Allahabad, Prayagraj, India.

SN Applied Sciences (2019) 1:1426| https://doi.org/10.1007/s42452-019-1283-9

Received: 19 June 2019 / Accepted: 14 September 2019 / Published online: 16 October 2019 
no chemical precursors and by-products, high purity, and one-step synthesis route $[14,18]$. In addition, many different types of NPs can be produced from metal, semiconductor and polymer nanostructures. Laser parameters such as wavelength, pulse repetition rate, pulse width and pulse energy affect and control the morphology and properties of the resulting NPs, including shape, size and distribution $[8,24]$. Therefore this physical technique can be used for the purpose of environment friendly methods of nanomaterial synthesis. Cuprous oxide $\left(\mathrm{Cu}_{2} \mathrm{O}\right)$ is one of the most stable copper oxides, because of its behavior similar to that of the P-type semiconductor [11], the theoretical direct band gap is $2.2 \mathrm{eV}$, and so the researchers' attention can be utilized (theoretical efficiency 18\%) [21, 23]. In this work, we have studied the synthesis of copper and its oxide nanomaterials by the pulse laser ablation (PLA) method and their characterization by XRD, UV-VIS and ATR-FTIR spectroscopy. The antibacterial test of prepared $\mathrm{Cu}_{2} \mathrm{O}$ and $\mathrm{CuO}$ NPs were performed against $\mathrm{S}$. aureus, MIC and $M B C$ value was also evaluated.

\section{Experimental sections}

\subsection{Materials}

The copper target (99.9\% purity) was purchased from Johnson Matthey (spec-pure), analytical grade double distilled water, polyethylene glycol 400 (PEG) from Merck and Mueller-Hinton Agar (MHA) and Muller Hinton broth (Himedia Pvt. Ltd) was used for the antibacterial assay.

\subsection{Laser ablation technique for synthesis of NPs}

Laser ablation of a metal target immersed in $20 \mathrm{~mL}$ of distilled water and other $20 \mathrm{~mL}$ ( $18 \mathrm{~mL}$ of distilled water and $2 \mathrm{~mL}$ of PEG) was carried out at room temperature and atmospheric pressure $(\sim 760 \mathrm{~mm} \mathrm{Hg})$. The copper target was illuminated with a focused Nd:YAG laser, which provided a $10 \mathrm{~ns}$ pulse at a wavelength of $1064 \mathrm{~nm}$ with a maximum pulse energy of $40 \mathrm{~mJ}$. The laser beam was focused vertically downward on the surface of the metal target using a dichroic mirror and focused using a convex quartz lens of $30 \mathrm{~cm}$ focal length, as setup shown in Fig. 1. The container and target were translated in a horizontal plane to evenly remove material and avoid surface pit formation [15].

\section{Instrumentation}

The UV-VIS absorption spectra of the synthesized NPs colloidal solution were recorded between spectral region 300-800 nm using a Perkin Elmer Lambda 35 dual beam spectrophotometer. The $\mathrm{Cu}_{2} \mathrm{O}$ and $\mathrm{CuO}$ NPs as well as PEG capping species were confirmed by infrared (IR) absorption spectra, which were recorded using FTIR spectrometer ( $A B B$, Bomem Inc.) equipped with ATR unit in the spectral
Fig. 1 Experimental setup of PLA used for the synthesis of copper oxides NPs

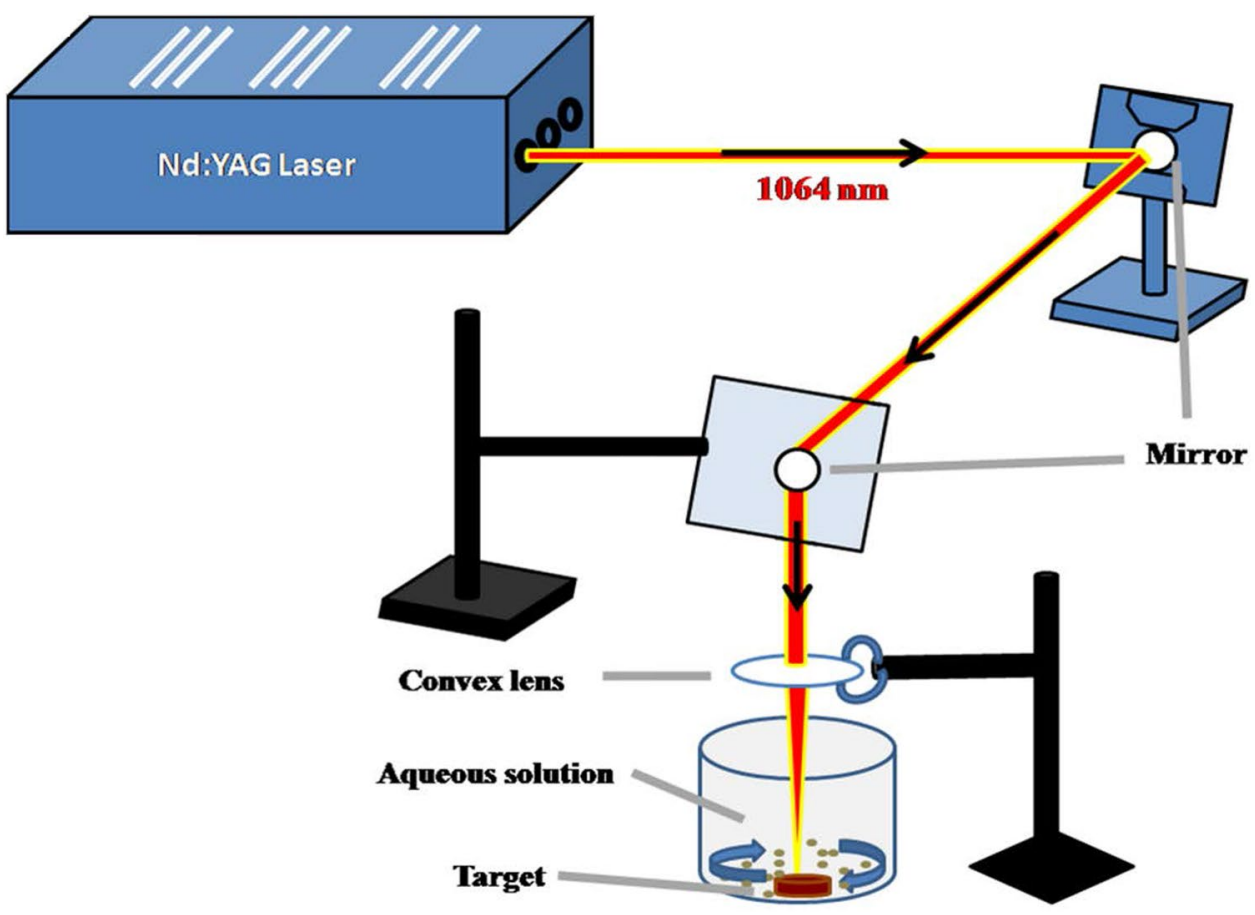


region $500-4000 \mathrm{~cm}^{-1}$ at a resolution of $4 \mathrm{~cm}^{-1}$. The X-ray diffraction (XRD) was performed using Proto A-XRD diffractometer equipped with CuKa $(\lambda=1.54 \AA)$ radiation. However, the crystalline size of copper oxides NPs were calculated as earlier $[1,15]$. The samples were scanned over a $2 \theta$ range of $20^{\circ}-80^{\circ}$ with a step size of $0.06^{\circ}$. In order to study PEG interaction on the surface of copper NPs, high-resolution transmission electron microscope (Tecnai G2-20, FEl Company, Netherland) operating at $200 \mathrm{kV}$ was used for the size and shape measurements of the prepared copper NPs. Samples for the transmission electron microscopy were prepared by keeping a drop of colloidal solution on the carbon-coated copper grid and drying under the IR lamp. However the synthesized copper concentration was analyzed using Inductively Coupled Plasma Mass Spectrometer (ICP-MS) (Thermo Fisher Scientific, Germany).

\subsection{Bactericidal test}

The Kirby-Bauer's disc diffusion assay of synthesized colloidal oxide of copper NPs (with PEG and without PEG) was performed to determine zone of inhibition. All experimental protocols were performed under adequate ascetic measures. For the disc diffusion method, approximately $5 \times 10^{6} \mathrm{CFU} \mathrm{m}{ }^{-1}, 100 \mu \mathrm{l}$ of $\mathrm{S}$. aureus suspension spread using sterilized cotton swabs over Mueller-Hinton agar plate. The disc ( $20 \mu \mathrm{L}$ capacity) was first dipped into the colloidal solution of copper NPs, followed by putting disc onto agar plate having uniform lawn of $S$. aureus suspension. The solution gradually defused spread to adjacent bacterial lawns and inhibited the growth of bacteria around the disc, which was then measured as antibacterial nature of the prepared NPs. The S. aureus culture plate was then incubated to overnight for $37^{\circ} \mathrm{C}$. The circular zone of bacterial growth inhibition/clear zone was expressed in terms of the average diameter of the zone of inhibition in millimetres [2].

The minimum inhibitory concentration (MIC) and minimum bactericidal concentration (MBC) of synthesized $\mathrm{Cu}_{2} \mathrm{O}$ and $\mathrm{CuO}$ were examined using procedure specified by [1]. The effect of copper NPs on S. aureus bacterial and growth kinetics was studied using optical density measurements at $600 \mathrm{~nm}$ of inoculated bacteria. The optical absorbance of control (copper NPs absent from inoculated bacteria) and test samples were measured for the period of $0-48 \mathrm{~h}$. The changes in optical density over time were used to produce growth curves at different concentration of $\mathrm{CuO}$ and $\mathrm{Cu}_{2} \mathrm{O}$ NPs against control. All the experiments were carried out in triplicate.

\section{Results and discussion}

\subsection{UV-Vis spectroscopy}

The UV-VIS absorption spectra of the synthesized two different colloidal copper oxides NPs in pure water and with $10 \%$ PEG were recorded within the wavelength region of $200-800 \mathrm{~nm}$. The recorded spectra are represented in Fig. 2a. This spectrum showed a peak at wavelength of $\sim 270 \mathrm{~nm}$ followed by another peak with cooperatively low intensity at $\sim 538 \mathrm{~nm}$. The peak at $270 \mathrm{~nm}$ is attributed to the characteristic Brillouin transition of $\mathrm{Cu}_{2} \mathrm{O}[3,6]$ and the surface plasmon resonance (SPR) peak at $538 \mathrm{~nm}$ of copper shows that the collective oscillation of the conducting
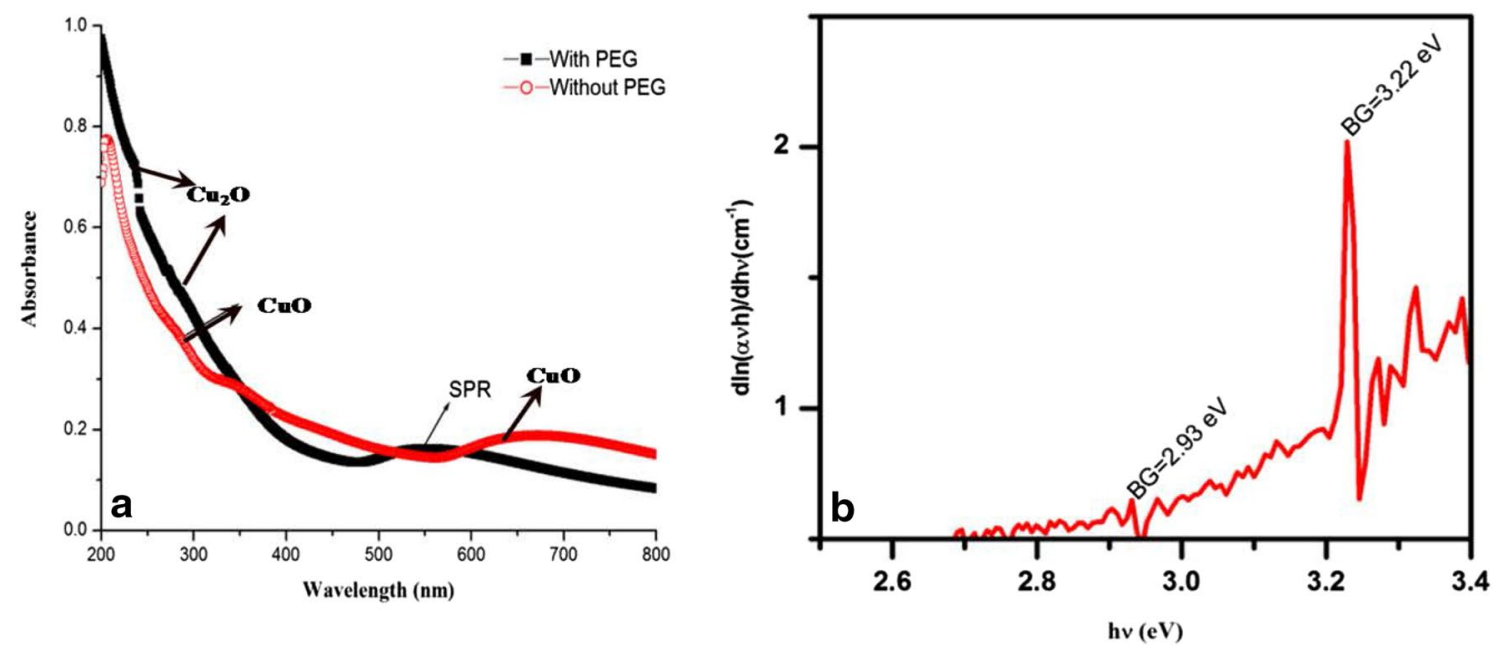

Fig. 2 a Recorded UV-VIS $\mathrm{Cu}_{2} \mathrm{O}$ and $\mathrm{CuO}$ and $\mathbf{b}$ corresponding dln(ahv)/d(hv) curve of synthesized colloidal oxide of CuO-NPs 
electrons on the surface of the nanosized particle absorbs visible electromagnetic waves which confirms copper particles are nano-sized [5]. Another absorption peak recorded at a wavelength of $640 \mathrm{~nm}$ found responsible for CuO-NPs species. The colloidal CuO-NPs are consistent with the peak reported in the $590-640 \mathrm{~nm}$ spectral regions $[5,18]$. It shows that the formation of a copper oxide nanocolloid produces peak at about $640 \mathrm{~nm}$ without a PEG medium. The simultaneous presence of spectral peaks at wavelengths of $270 \mathrm{~nm}$ and $640 \mathrm{~nm}$ strongly supports the presence of CUO NPs. In case of PEG assisted synthesis, the small absorption humps were seen around 230-270 $\mathrm{nm}$ and the same time another absorption SPR peak at $538 \mathrm{~nm}$ which confirms the presence of $\mathrm{Cu}_{2} \mathrm{O}$ and $\mathrm{Cu}$ NPs. However, PEG exhibited capability to restrict the oxidation of copper NPs during the PEG-mediated copper target ablation, therefore initially trace amount of $\mathrm{Cu}_{2} \mathrm{O}$ was observed. It might be possible to form a Cu NPs core shell surrounded by a thin layer of $\mathrm{Cu}_{2} \mathrm{O}$ NPs whose outer surface continuously interacts with dissolved oxygen in the aqueous medium and after passing few days, thin layer of $\mathrm{Cu}_{2} \mathrm{O}$ might grow and finally CuNPs become converted into pure $\mathrm{Cu}_{2} \mathrm{ONPs}$.

The optical band gap of synthesized CuO-NPs was estimated to employing absorption data, the absorption coefficient, (a) of the colloidal solution of CuO-NPs under the Beer's law, is related to its band gap energy by:

$\alpha=\mathrm{A}(\mathrm{h} \nu-\mathrm{Eg})^{\mathrm{n}} / \mathrm{h} \nu$

where $A$ is a constant, $E_{g}$ is the band gap of material, and the exponent $n$ may have the values $1 / 2,2,3 / 2$, and 3 corresponding to allowed direct, allowed indirect, forbidden direct, and forbidden indirect semiconductor, respectively.

The region of fundamental absorption, which corresponds to the electronic transition from top of the valance band to the bottom of conduction band, can be utilized to determine the band gap energy of the material using above relation. The hv derivative of $\ln (a h v)=\ln n A\left(h v-E_{g}\right)$ makes following expression

$\frac{\mathrm{D}\{\ln (\alpha \mathrm{h} \nu)\}}{d(\mathrm{~h} \nu)}=\frac{\mathrm{n}}{(\mathrm{h} \nu-\mathrm{Eg})}$

The plot of $d\{\ln (a h v)\} / d(h v)$ versus hv shows a divergence at energy equal to the band gap $E_{g}$ corresponding to the electronic transition as displayed in Fig. $2 \mathrm{~b}$. This plot suffers comparatively less error in the band gap determination as compared to the Tauc plot. Band gap of the CuONPs obtained by LA-PLA of copper in distilled water has band gap energy of $3.22 \mathrm{eV}$.

\subsection{X-ray diffraction}

The X-ray diffraction pattern of the PEG mediated laser ablated samples were recorded and analyzed after 15 days of sample preparation. The peak positions with 2 theta values of $12.0^{\circ}, 14.7^{\circ}, 17.03^{\circ}, 24.1^{\circ}$ and $28.34^{\circ}$ were indexed as (110), (111), (200), (220) and (222) planes, which are in good agreement with those of powder $\mathrm{Cu}_{2} \mathrm{O}$ NPs obtained from the International Center of Diffraction Data card (JCPDS File No. 03-0898) confirming the formation of a crystalline cubic phase of $\mathrm{Cu}_{2} \mathrm{O}$ with a cuprite structure shown in Fig. 3 [10]. There was no observed any additional diffraction peaks showing its high purity. The average crystalline size of $15 \mathrm{~nm}$ and cubic cuprous oxides $\left(\mathrm{Cu}_{2} \mathrm{O}\right)$ were calculated from XRD peaks using Debye-Scherrer's formula. It was clearly observed that the initially prepared copper NPs slowly oxidized and were converted in the form of cuprous oxide.

\subsection{Transmission electron microscopy}

TEM is well known technique for imaging solid materials at the level of atomic resolution. This technique was used visualize the size and shape of the oxides of copper NPs. The small size clusters of nanorods of PEG assisted copper NPs are shown in Fig. 4a, b. The TEM micrograph showed most of the copper NPs are rod shaped with the length ranges between 30 and $50 \mathrm{~nm}$ and width in range of 8-15 nm. As prepared CuO NPs were visualized round shape particles through TEM micrograph, with average size range of $22 \mathrm{~nm}$ It can be attributed that the small widths of nanorods could directly be penetrated to the cell wall of bacteria, which may disrupt the function

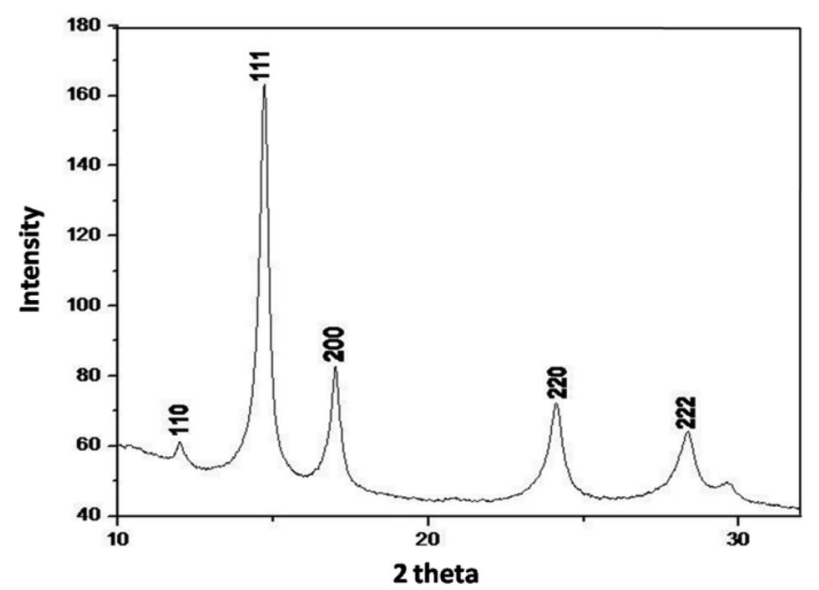

Fig. 3 X-ray diffraction of $\mathrm{Cu}_{2} \mathrm{O}$ NPs prepared in the presence of PEG 

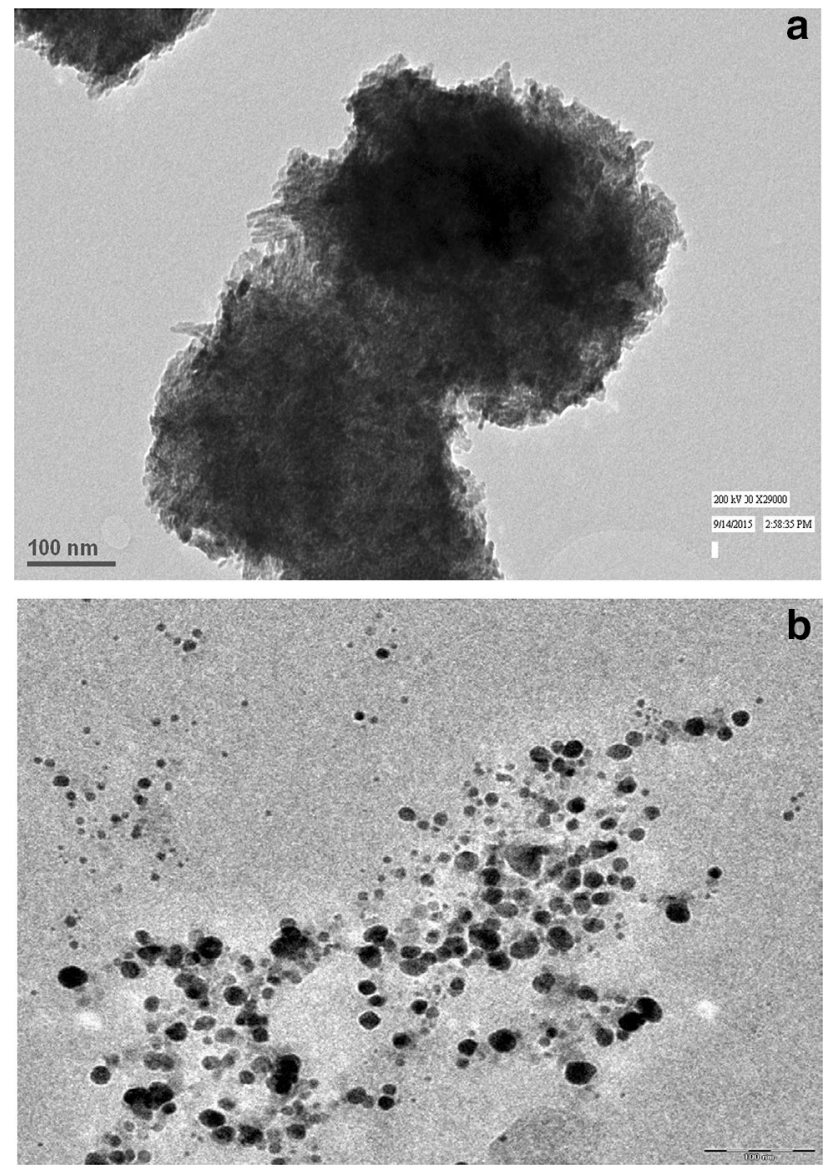

of bacterial cell that leads toxic effect to the bacteria, whereas, larger size of $\mathrm{CuO}$ may be less effective due to slower penetration into the bacterial cells.

\subsection{ATR-FTIR}

ATR-FTIR spectrum of colloidal sample of copper oxides were recorded in the spectral region $400-4000 \mathrm{~cm}^{-1}$ and it has been represented in Fig. 5. The three characteristic bands were observed at $432 \mathrm{~cm}^{-1}, 497 \mathrm{~cm}^{-1}$, and $613 \mathrm{~cm}^{-1}$ which were assigned to the $A_{u}$ mode, $B_{u}$ mode, and other $B_{u}$ mode of $\mathrm{CuO}$. Similar observation were also in accordance to the findings of Kliche and Popovic [9]. In case of without PEG the IR absorptions at around $440 \mathrm{~cm}^{-1}$, $497 \mathrm{~cm}^{-1}$ and $530 \mathrm{~cm}^{-1}$ can be attributed to the lattice vibration of the oxide of copper, confirming the formation of pure CuO-NPs present as thin layer [25]. The similar study done by Dang et al. [5] states that the possibility of electrostatic interaction through ester bond of PEG to copper leads to very slow oxidation of copper NPs. The ester bond characteristics were found at wave-number around $1090 \mathrm{~cm}^{-1}$ with of PEG assisted $\mathrm{Cu}_{2} \mathrm{O}$ synthesis which is in favor of the observations reported by Dang et al. [5].

Fig. 4 TEM micrograph of $\mathbf{a} \mathrm{Cu}_{2} \mathrm{O}$ NPs prepared in the presence of PEG b CUO NPs prepared absence of PEG

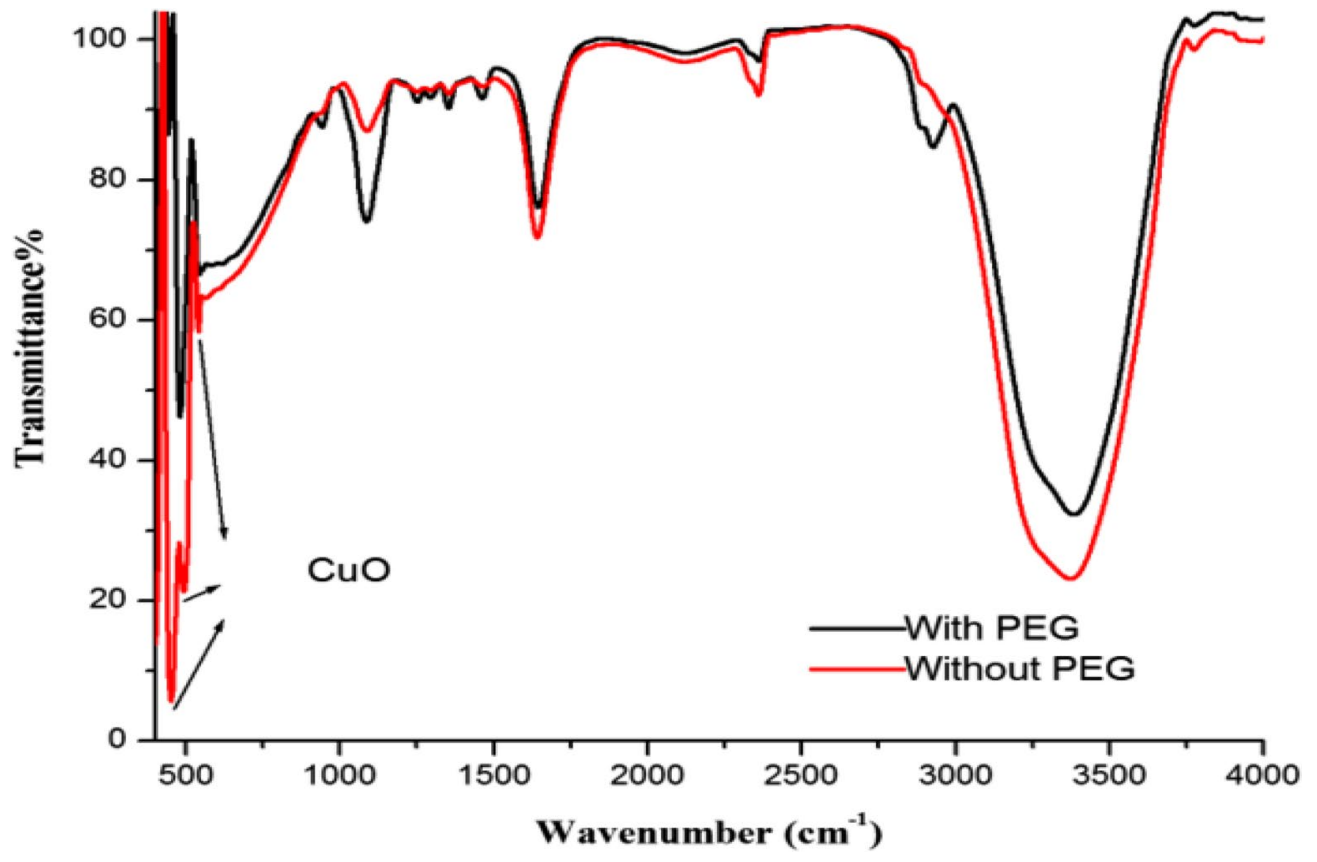

Fig. 5 Recorded ATR-FTIR spectra of the synthesized colloidal oxide of copper NPs 


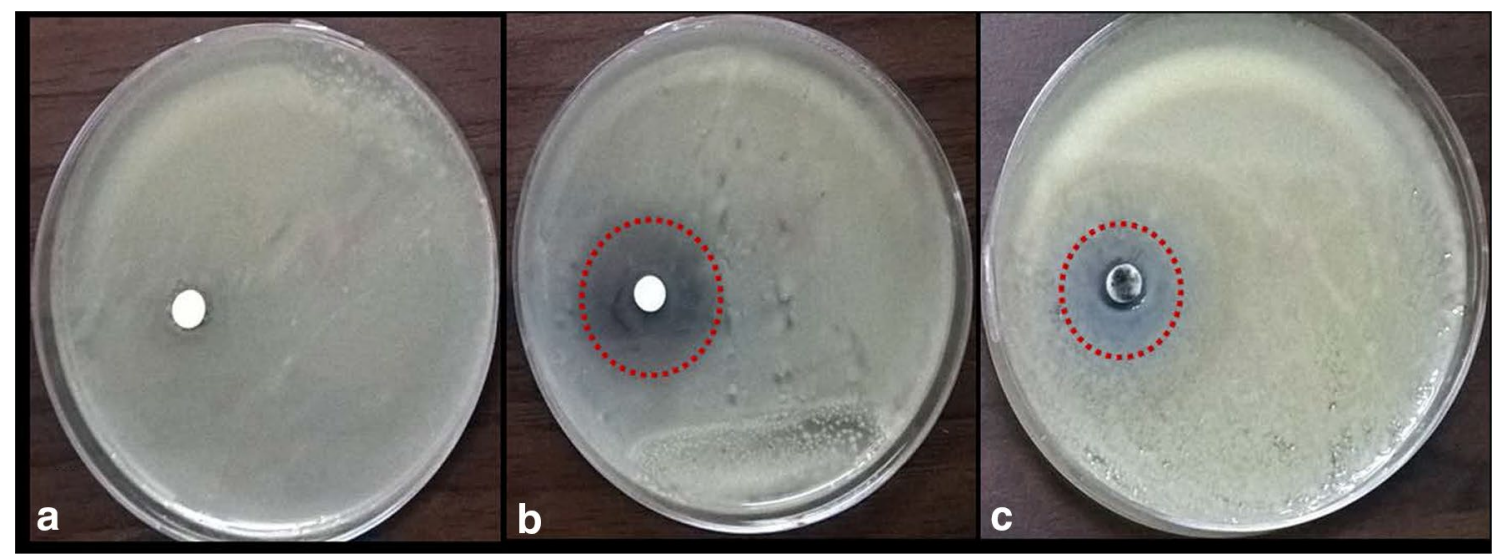

Fig. 6 Disc diffusion essay of a control, $\mathbf{b} \mathrm{Cu}_{2} \mathrm{O}$ NPs and $\mathbf{c} \mathrm{CuO}$ NPs synthesized by LAPLA

\section{Antibacterial}

\subsection{Disc diffusion}

The synthesized $\mathrm{Cu}_{2} \mathrm{O}$ and $\mathrm{CuO}$ were further tested against S. aureus Gram-positive bacteria as the research object using Kirby-Bauer's standard disc diffusion method. As the, Gram positive bacteria composed of thick peptidoglycan layer with rigid structure leads slower penetration of NPs in comparison to Gram-negative bacteria having thin layer of peptidoglycan, which allows comparatively faster penetration of NPs [12]. The discs containing $20 \mu \mathrm{l}$ of $\mathrm{Cu}_{2} \mathrm{O}$ and $\mathrm{CuO}$ NPs with concentration $35 \mu \mathrm{g} / \mathrm{mL}$ were placed over the bacterial lawn and incubated for overnight. Discs soaked with both $\mathrm{Cu}_{2} \mathrm{O}$ and $\mathrm{CuO}$ types of NPs $35 \pm 0.86 \mu \mathrm{g} /$ $\mathrm{mL}$ remarkably inhibited the growth of test bacteria. The highest zone of inhibition $10 \mathrm{~mm}$ was recorded with $\mathrm{Cu}_{2} \mathrm{O}$ NPs, which was followed by $7 \mathrm{~mm}$ with $\mathrm{CuO}$ NPs after $24 \mathrm{~h}$ of incubation. The diffusion of both NPs was clearly visible with light blackish colour making inhibitory zone. The significant zone of inhibition was observed $\sim 7 \mathrm{~mm}$ and $10 \mathrm{~mm}$ around the disc containing $\mathrm{CuO}$ and $\mathrm{Cu}_{2} \mathrm{O}$ respectively (Fig. 6).

\subsection{Bacterial growth curve}

Dose dependent growth kinetics of $S$. aureus was variably influenced by the treatments with variable concentrations of $\mathrm{CuO}$ and $\mathrm{Cu}_{2} \mathrm{O}$ NPs which has been illustrated in Fig. $7 \mathrm{a}$, b. Bacterial growth was reduced with increasing concentration of both types of copper oxide NPs. The introduction of $\mathrm{Cu}_{2} \mathrm{O} \mathrm{NPs}$ remarkably affected the growth kinetics of $S$. aureus strain as compared to the negative control (culture grown in absence of copper NPs). At their respective MBC values, there was no visible bacterial growth observed up to the time of $28 \mathrm{~h}$, that represents the bactericidal
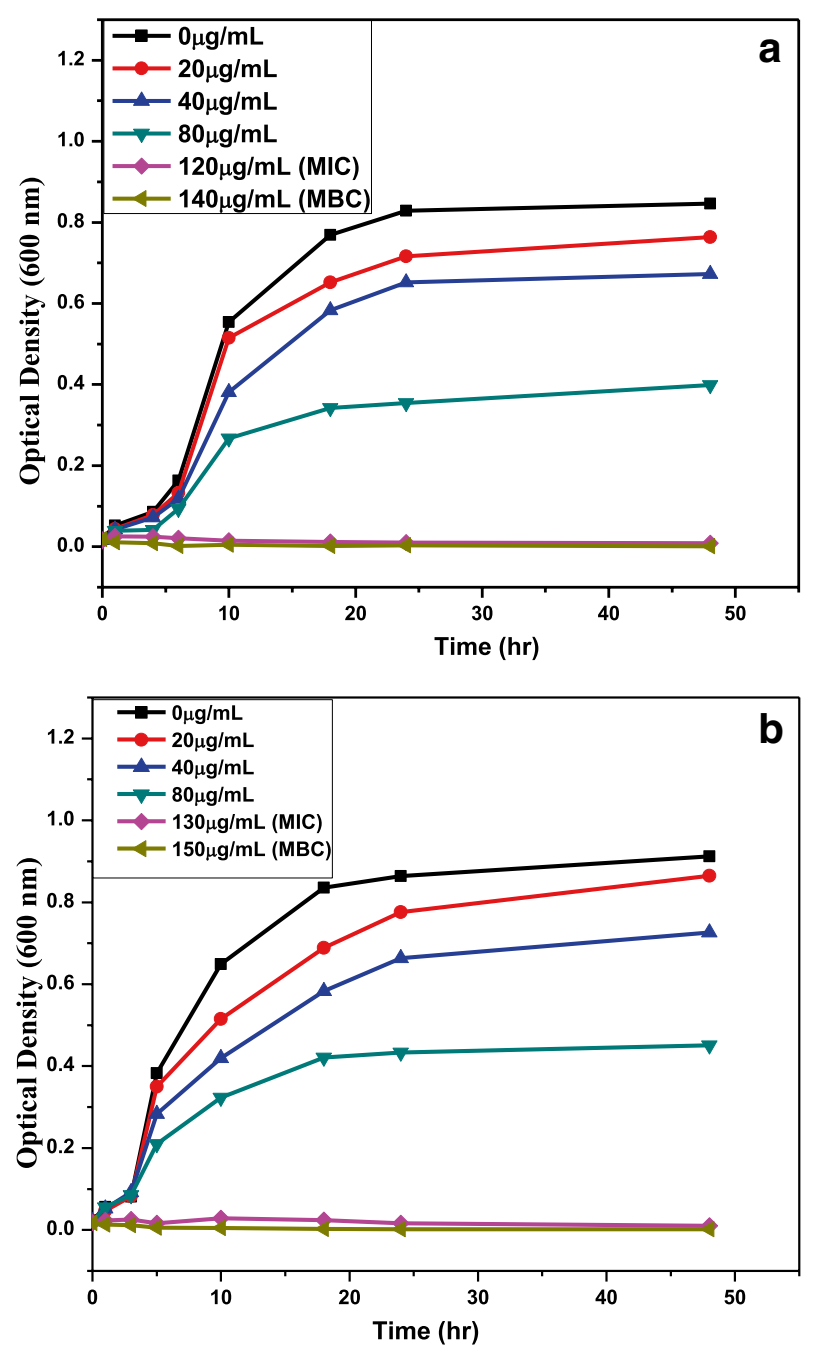

Fig. 7 Growth profile of S. aureus bacterial strain in presence of varying concentrations of $\mathbf{a} \mathrm{CuO} \mathrm{NPs}$ and $\mathbf{b} \mathrm{Cu}_{2} \mathrm{O}$ NPs

\section{SN Applied Sciences}


concentration for the $S$. aureus strain. The initial concentration 20,40 and $80 \mu \mathrm{l} / \mathrm{mL} \mathrm{Cu}_{2} \mathrm{O}$ NPs were responsible for the $12 \%, 25 \%$ and $85 \%$ reduction of $S$. aureus density as compared to control sets respectively. Further, increasing concentration of $\mathrm{Cu}_{2} \mathrm{O} \mathrm{NPs}$ at the level of $120 \mu \mathrm{l} / \mathrm{mL}$ and $140 \mu \mathrm{l} / \mathrm{mL}$ caused complete absence of bacterial growth as these concentrations represent MIC and MBC values respectively. Similarly, the initial concentration of $\mathrm{CuO}$ 2040 and $80 \mu \mathrm{l} / \mathrm{mL}$ leads to reduce the growth of same bacteria up to $10 \%, 18 \%$ and $70 \%$ respectively. Whenever, these $\mathrm{CuO}$ concentrations increased up to the level of $130 \mu \mathrm{l} / \mathrm{mL}$ and $150 \mu \mathrm{l} / \mathrm{mL}$ resulted as the MIC and MBC values respectively. The above result is the good agreement with Surapaneni et al. [17]. They suggested that the intracellular protein have high affinity towards $\mathrm{Cu}_{2} \mathrm{O}$ in compare to $\mathrm{CuO}$. In other hand, the function of inhibitory and bactericidal nature of both copper oxides NPs might be due to smaller width of rod shaped NPs. The unique rod shaped $\mathrm{Cu}_{2} \mathrm{O}$ NPs have influenced and the facilitated the penetration of NPs into the bacterial cell wall. Such phenomenon of rapid penetration of rod shaped NPs leads to disrupt cellular integrity might have to contribute in ROS generation and protein binding. These actions can cause improper metabolism and replication of their genetic materials consequently, cell death.

\section{Conclusion}

The UV-VIS absorption spectra carried out without PEG and PEG have clearly indicated the formation of $\mathrm{Cu}_{2} \mathrm{O}$ NPs and CuO NPs. Initially copper NPs slowly oxidize and convert into stable cuprous oxide NPs have high purity, smaller in size than synthetic oxides due to the continuous capping of ablated copper in presence of PEG. On the other hand, in the absence of PEG CuO-NPs was formed due to the natural oxidation of the dissolved oxygen in medium. The comparable growth kinetics of $\mathrm{S}$. aureus bacteria were also studied in the presence of $\mathrm{CuO}$ and $\mathrm{Cu}_{2} \mathrm{O}$ $\mathrm{NPs}$. The small size, rod shape $\mathrm{Cu}_{2} \mathrm{O} \mathrm{NPs}$ have remarkable bactericidal capacity (MIC $120 \mu \mathrm{l} / \mathrm{mL}$ and MBC $140 \mu \mathrm{l} /$ $\mathrm{mL}$ ) against $S$. aureus bacteria. These remarkable antibacterial properties of synthesized stable $\mathrm{Cu}_{2} \mathrm{O}$ NPs can be employed in the field of clinical, medical and environment.

Acknowledgements The first author (Abhishek K. Bhardwaj) is highly thankful to VBS Purvanchal University for providing Purvanchal University Postdoctoral Fellowship (PUPDF) (Grant No. 01 PUPDF/ EVS) and facility from University of Allahabad, Prayagraj to carry out research. Authors are also thankful to K. K. Pandey from Cyclotron Centre of Raja Ramanna Centre for Advanced Technology (RRCAT), Indore, India for providing XRD facility.

\section{Compliance with ethical standards}

Conflict of interest The authors declare that there is no conflict of interest.

\section{References}

1. Bhardwaj AK, Shukla A, Maurya S, Singh SC, Uttam KN, Sundaram S, Singh MP, Gopal R (2018) Direct sunlight enabled photobiochemical synthesis of silver nanoparticles and their bactericidal efficacy: photon energy as key for size and distribution control. J Photochem Photobiol B 188:42-49

2. Bhardwaj AK, Shukla A, Mishra RK, Singh SC, Mishra V, Uttam KN, Singh MP, Sharma S, Gopal R (2017) Power and time dependent microwave assisted fabrication of silver nanoparticles decorated cotton (SNDC) fibers for bacterial decontamination. Front Microbiol 3(8):330

3. Ching W, Xu Y-N, Wong K (1989) Ground-state and optical properties of $\mathrm{Cu}_{2} \mathrm{O}$ and $\mathrm{CuO}$ crystals. Phys Rev B 40:7684

4. Cioffi N, Rai M (2012) Nano-antimicrobials: progress and prospects. Springer, Berlin

5. Dang TMD, Le TTT, Fribourg-Blanc E, Dang MC (2011) Synthesis and optical properties of copper nanoparticles prepared by a chemical reduction method. Adv Nat Sci Nanosci Nanotechnol 2:015009

6. Ito T, Kawashima T, Yamaguchi H, Masumi T, Adachi S (1998) Optical properties of $\mathrm{Cu}_{2} \mathrm{O}$ studied by spectroscopic ellipsometry. J Phys Soc Jpn 67:2125-2131

7. Jia B, Mei Y, Cheng L, Zhou J, Zhang L (2012) Preparation of copper nanoparticles coated cellulose films with antibacterial properties through one-step reduction. ACS Appl Mater Interfaces 4:2897-2902

8. Khashan KS, Sulaiman GM, Abdulameer FA (2016) Synthesis and antibacterial activity of $\mathrm{CuO}$ nanoparticles suspension induced by laser ablation in liquid. Arab J Sci Eng 41:301-310

9. Kliche G, Popovic Z (1990) Far-infrared spectroscopic investigations on CuO. Phys Rev B 42:10060

10. Kooti M, Matouri L (2010) Fabrication of nanosized cuprous oxide using Fehling's solution. Sci Iran 17(1):73-78

11. Mahmoodi S, Elmi A, Hallaj-nezhadi S (2018) Copper nanoparticles as antibacterial agents. J Mol Pharm Org Process Res 6:1-7

12. Pandey JK, Swarnkar R, Soumya K, Dwivedi P, Singh MK, Sundaram S, Gopal R (2014) Silver nanoparticles synthesized by pulsed laser ablation: as a potent antibacterial agent for human enteropathogenic gram-positive and gram-negative bacterial strains. Appl Biochem Biotechnol 174:1021-1031

13. Patel M, Nagare B, Bagul D, Haram S, Kothari D (2005) Controlled synthesis of $\mathrm{Cu}$ nanoparticles in fused silica and BK7 glasses using ion beam induced defects. Surf Coat Technol 196:96-99

14. Popov A, Tselikov G, Al-Kattan A, Kabashin A, (2019) Femtosecond laser-ablative synthesis of plasmonic Au and TiN nanoparticles for biomedical applications. Synthesis and photonics of nanoscale materials XVI. International Society for optics and photonics, p 1090708

15. Shukla A, Bhardwaj AK, Pandey B, Singh S, Uttam K, Shah J, Kotnala R, Gopal R (2017) Laser synthesized magnetically recyclable titanium ferrite nanoparticles for photodegradation of dyes. $J$ Mater Sci Mater Electron 28:15380-15386

16. Sonawane GH, Patil SP, Sonawane SH (2018) Nanocomposites and its applications. Applications of nanomaterials. Elsevier, Amsterdam, pp 1-22 
17. Surapaneni M, Prachi K, Swati C, Nagarajan P (2015) Understanding the pathway of antibacterial activity of copper oxide nanoparticles. RSC Adv 5:12293

18. Swarnkar R, Singh S, Gopal R (2011) Effect of aging on copper nanoparticles synthesized by pulsed laser ablation in water: structural and optical characterizations. Bull Mater Sci 34:1363-1369

19. Tamilvanan A, Balamurugan K, Ponappa K, Kumar BM (2014) Copper nanoparticles: synthetic strategies, properties and multifunctional application. Int J Nanosci 13:1430001

20. Tang Y, Ruan H, Huang Z, Shi D, Liu H, Chen S, Zhang J (2018) Fabrication of high-quality copper nanowires flexible transparent conductive electrodes with enhanced mechanical and chemical stability. Nanotechnology 29:455706

21. Teng F, Hu K, Ouyang W, Fang X (2018) Photoelectric detectors based on inorganic p-type semiconductor materials. Adv Mater 30:1706262

22. Tilaki R, Mahdavi S (2007) Size, composition and optical properties of copper nanoparticles prepared by laser ablation in liquids. Appl Phys A 88:415-419
23. Vivas L, Chi-Duran I, Enriquez J, Barraza N, Singh DP (2019) Ascorbic acid based controlled growth of various $\mathrm{Cu}$ and $\mathrm{Cu}_{2} \mathrm{O}$ nanostructures. Mater Res Express 6(6):065033

24. Zeng H, Du XW, Singh SC, Kulinich SA, Yang S, He J, Cai W (2012) Nanomaterials via laser ablation/irradiation in liquid: a review. Adv Func Mater 22:1333-1353

25. Zhang H, Zhu Q, Zhang Y, Wang Y, Zhao L, Yu B (2007) One-pot synthesis and hierarchical assembly of hollow $\mathrm{Cu}_{2} \mathrm{O}$ microspheres with nanocrystals-composed porous multishell and their gas-sensing properties. Adv Func Mater 17:2766-2771

26. Zhu H, Zhang C, Yin Y (2005) Novel synthesis of copper nanoparticles: influence of the synthesis conditions on the particle size. Nanotechnology 16:3079

Publisher's Note Springer Nature remains neutral with regard to jurisdictional claims in published maps and institutional affiliations. 